\title{
Performance Analysis of Different Wavelet Families Over Fading Environments for Mobile WiMAX System
}

\author{
Harpreet Kaur ${ }^{1}$, Manoj Kumar ${ }^{2}$, Ajay K Sharma ${ }^{3}$ and Harjit P. Singh ${ }^{4}$ \\ ${ }^{1}$ Department of Computer Science and Engineering, \\ DAV Institute of Engineering and Technology, Jalandhar-144008, India \\ ${ }^{2}$ CT Institute of Engineering Management and Technology, Jalandhar, India \\ ${ }^{3}$ National Institute of Technology, New Delhi, India \\ ${ }^{4}$ Department of Electronic and Communication Engineering, \\ CT Institute of Engineering Management and Technology, Jalandhar, India \\ ${ }^{1}$ harpreet_daviet@yahoo.in, ${ }^{2}$ drmanojkumarindia@gmail.co \\ ${ }^{3}$ sharmaajayk@rediffmail.com, ${ }^{4}$ harjit_nit@yahoo.co.in
}

\begin{abstract}
Orthogonal Frequency Division Multiplexing (OFDM) has made tremendous improvement possible in wireless technology. Wavelet analysis is used as an alternative to Fourier analysis in OFDM system to transform and map data onto orthogonal subcarriers, as it is a time-frequency domain operation thus it offers the advantages of optimal flexibility with less complexity. This paper presents performance analysis in terms of Bit Error rate (BER) of different wavelet families in OFDM System under the joint effect of path loss, multipath fading and noisy environment for Mobile WiMAX. The results obtained show that the performance of the mobile-multipath environments for 16QAM modulation schemes is enhanced as Daubechies and Biorthogonal wavelet families offers lower BER with different Path loss model. The performance measurements and analysis was done in simulation developed in MATLAB.
\end{abstract}

Keywords: OFDM, FFT, DWT, Path Loss, multipath-fading, mobile WiMAX

\section{Introduction}

The major requirements of the communication which are also the challenges for the next generation of wireless system is to have a better coverage and quality, to be more bandwidth efficient due to its ever-increasing demand in future wireless services, and to deploy in diverse environment. OFDM is one of the powerful Multi-Carrier Modulation (MCM) technique having high speed transmission capability with bandwidth efficiency and robust performance in multipath fading environments. Mobile WiMAX (WiMAX stands for Worldwide Interoperability for Microwave Access) standard, IEEE 802.16e have also adopted OFDM to facilitates high data rate transmission and to improve the multipath performance Conventional OFDM system based on Fast Fourier Transform (FFT)/Inverse Fast Fourier Transform (IFFT) offers several other advantages also including high spectral efficiency and mitigation the effects of Inter Channel Interference (ICI) and Inter Symbol Interference (ISI) with use of Cyclic Prefix (CP). However it also suffers from certain limitations including its high sensitivity to timing and frequency offsets which lead to high BER and a higher Peak to Average Power Ratio (PAPR) [1]. Khalid et al [2] observed that DWT reduced PAPR problem of OFDM thus suggested it as replacement to the FFT process in multi carrier modulation OFDM system. Saad et al [3] analyzed that bandwidth efficiency of wavelet based OFDM was improved as it do not require cyclic prefixes. Kaizuran et al [3] studied the computational complexity of wavelet based OFDM by exploring its orthonormal base and perfect reconstruction 
properties and proposed it as a better alternative substitutions for FFT based OFDM. The performance of different wavelets was studied for multipath propagation over the wireless fading channels in [4] and the authors also suggested preferring orthogonal wavelets as they have the capability to reduce the power of ISI and ICI which were caused due to loss of orthogonality between the carriers. Gupta et al [5] analyzed the impact of DWT and DCT-OFDM system for two modulation formats BPSK and QPSK in an AWGN environment and they examined that performance of Wavelet Transform (Haar) -OFDM with QPSK was better than BPSK modulation format. Khan et al [7] observed that wavelet packet modulation (WPM) offered much lower side lobes in transmitted signal thus decreases narrowband interference (NBI) and ICI for several multipath wireless channels. Oltean et al [8] carried out a detailed survey on performance of wavelets with various communications medium and evaluated the channel with maximum Doppler shift, to conclude that a balance was needed to be maintained between ISI and its time variability. The effect of Wavelet Packet Transform (WPT) using various number of constellation points for QAM modulation was observed in [9]. Helaly et al [10] proposed that wavelet packet modulation performs better than conventional OFDM when the signals are passed through a fading channel and a nonlinear High Power Amplifier (HPA). Broughton et al [11] observed complexity of Discrete Wavelet Transform (DWT) as an $\mathrm{O}(\mathrm{N})$ which was much less than that of FFT having complexity as $\mathrm{O}\left(\mathrm{Nlog}_{2} \mathrm{~N}\right)$ and suggested that the wavelet transform could be efficiently applied for the wireless communication systems. Anoh et al [12] investigated various wavelet families such as Haar, Biorthogonal, Daubechies, Reverse-Biorthogonal, Symlet, and Coiflets for OFDM system design for an AWGN channel. The authors proposed that higher order of Daubechies, Biorthogonal, Reverse Biorthogonal and Symlet wavelets can perform better provided higher channel bandwidth is available. Gupta et al [13] evaluated the performance of various wavelet families and it was suggested that Haar, Daubechies, Coiflet and Symlet wavelet families perform better in multipath fading channel and effectively combat different burst errors caused by phase noise without deteriorating the channel capacity for different channel estimation techniques.

In the present work comparison of the performance of the different wavelet families based OFDM system considering joint impact of Path Loss, multipath fading and noise environment in wireless channel is analyzed for Mobile WiMAX using 16-QAM modulation schemes through extensive computer simulation.

\section{Discrete Wavelet Transform Based OFDM System}

DWT must have the orthonormal bases to satisfy the perfect reconstruction properties to be considered in the OFDM system. There are several types of wavelets transforms widely used such as Haar, Biorthogonal, Daubechies, Reverse Biorthogonal, Symlet wavelets etc. The wavelet transform is obtained by filtering the signal through a series of digital filters having different scales. This scaling operation is done by sub sampling via changing the resolution of the signal. The input sequences is converted into low pass and high pass sub bands during decomposition, each band consist of half the number of samples in the original sequence. The high pass filter associated with scaling function denoted by $d[n]$ is called as detailed coefficients, while the low pass filter denoted by a $[n]$ is called as approximated coefficients at each level. This process of filtering and decimation continue until the desired level is achieved. The length of the signal decides the number of levels. Then all the coefficients of low pass and high pass are combined starting from the last level of decomposition to get DWT of signal [14]. 


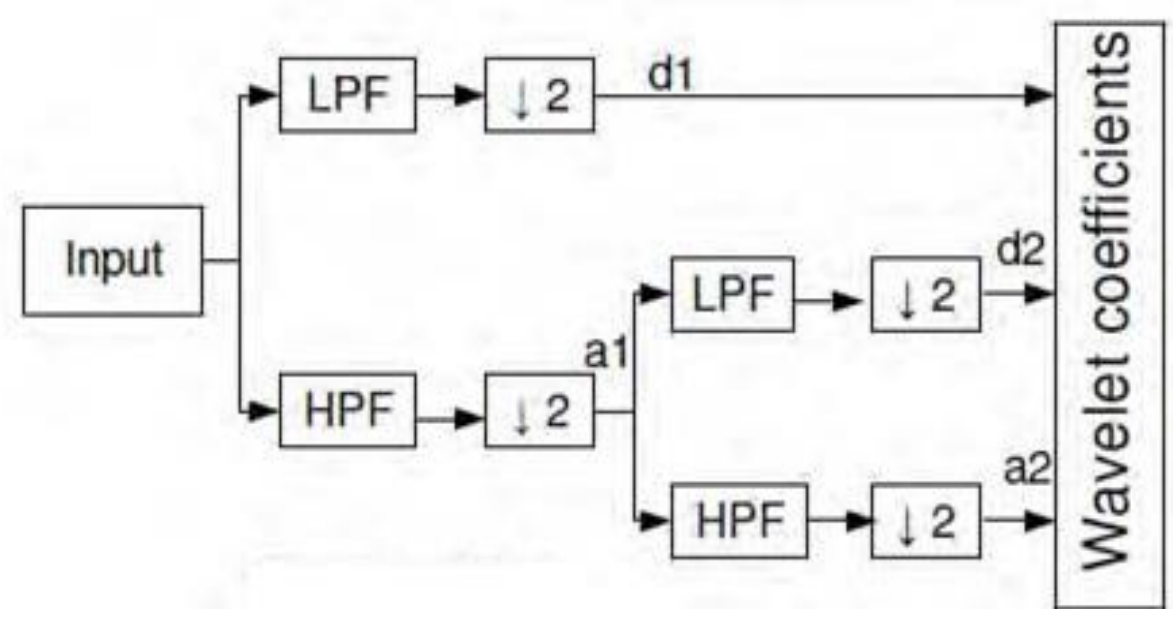

Figure 1. Decomposition

DWT of $x(n)$ is represented as:

$$
\mathrm{x}(\mathrm{m}, \mathrm{k})=\Sigma_{\mathrm{n}} \mathrm{x}(\mathrm{n}) 2^{\frac{\mathrm{m}}{2}} \psi\left(2^{\mathrm{m}} \mathrm{n}-\mathrm{k}\right)
$$

Both the high pass and low pass filters in the Discrete Wavelet Transform acts as Quadrature Mirror Filters (QMF). The inverse wavelet transform is used to build the transmitted symbol. The processing of a signal through inverse wavelet transform is usually referred to as synthesizing into wavelet coefficients, while the reverse operation is called analyzing from wavelet coefficients. Approximated and detailed coefficients are up sampled by two at every level, then they are passed through the low pass and high pass filters (synthesis) and finally they are added. This process of reconstruction is the reverse process of decomposition, so it has the same number of levels as in the decomposition process to obtain the original signal [14].

The reconstruction of the transmitted signal can be estimated through IDFT as:

$$
\mathrm{x}(\mathrm{n})=\sum_{m=-\infty}^{\infty} \sum_{n=-\infty}^{\infty} X(m, k) 2^{\frac{m}{2}} \psi\left(2^{m} n-k\right)
$$

(2)

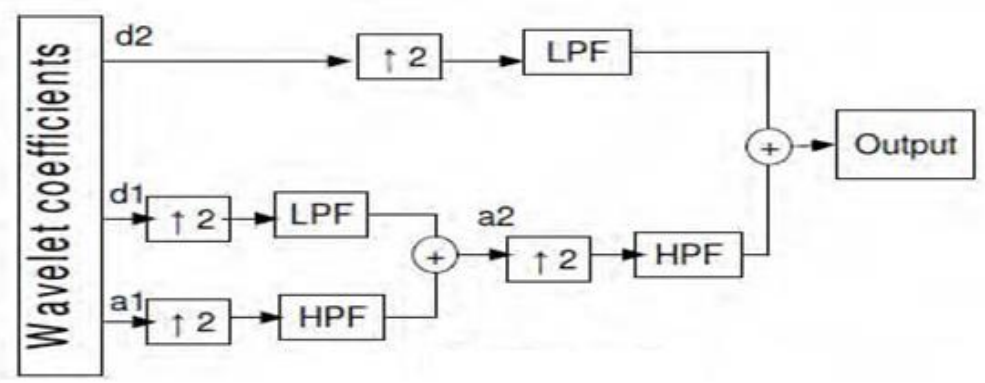

Figure 2. Reconstruction 


\section{Channel Model}

The wireless channel is vulnerable to a variety of transmission obstructions which restrict the data rate, reliability and the range of the wireless transmission. These factors decide to what extent they will affect the transmission depending upon the mobility of the transmitter and receiver and environmental conditions. Realistic modeling of a channel is crucial for accurate simulation of wireless networks.

\subsection{Path Loss}

For a transmitted signal through any radio link, path loss serves as the main factor for representation of its propagation. Radio propagation models primarily focus on modeling the signals on perceptive of the path loss over different terrain or path, atmospheric conditions, obstructions and other factors including distance from the transmitter etc. Although numerous path loss models are available, actual environments are too complex to model precisely. Different empirical models that have been developed based on the measurements taken in various real urban, suburban and rural environments. For wireless communications most commonly used Empirical Path loss methods are Hata model and Okumura model which are analyzed and compared in this paper.

\subsubsection{Hata Propagation Model}

The Hata model is best accurate within frequency range of 150 to $1500 \mathrm{MHz}$, the height of base station antenna ranges from 30 to $200 \mathrm{~m}$; the distance from the base station is in the range from 1 to $20 \mathrm{Km}$ and the height of mobile antenna ranges from 1 to $10 \mathrm{~m}$. As illustrated in equations (3-5), number of path loss mathematical models is created by Hata for urban, suburban and rural/open country environments, respectively.

For urban areas the Hata model formulated is as follows:-

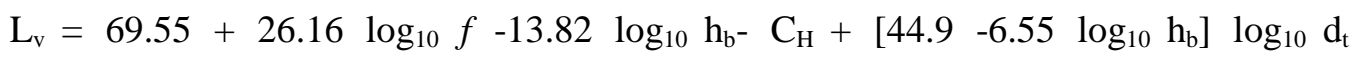

For small or medium sized city,

$$
\mathrm{C}_{\mathrm{H}}=0.8+\left(1.1 \log _{10} f-0.7\right) \mathrm{h}_{\mathrm{m}}-1.56 \log _{10} f
$$

And for large cities,<smiles>[MgH]</smiles>

$$
=\left\{\begin{array}{l}
\left.8.29\left(\log _{10}\left(1.54 h_{m}\right)\right)^{2}\right)-1.1, \text { if } 150 \leq f \leq 200 \\
\left.3.2\left(\log _{10}\left(11.74 h_{m}\right)\right)^{2}\right)-4.97, \text { if } 150 \leq f \leq 200
\end{array}\right.
$$

where $L_{v}$ is Path loss in $d B, \mathrm{~h}_{\mathrm{b}}$ is height of base station antenna in meter, $\mathrm{h}_{\mathrm{m}}$ is height of mobile station antenna in meter, $f$ is the frequency of transmission in $\mathrm{MHz}$, $C_{H}$ is Antenna height correction factor and $d_{t}$ is the distance between the base and mobile stations in $\mathrm{Km}$. 


\subsubsection{Okumura Model}

Okumura model is planned for use in the frequency range of 200 to $1920 \mathrm{MHz}$ when the mobile station antenna height is between 1 to $10 \mathrm{~m}$, base station antenna height is between 30 to $1000 \mathrm{~m}$ and link distance is between 1 to $100 \mathrm{Km}$. This model is formally expressed in equation (9).

The equation describing the median path loss in $\mathrm{dB}$ for Okumura model is (6)

$\mathrm{L}=\mathrm{L}_{\mathrm{SL}}+\mathrm{X}_{\mathrm{MU}}-\mathrm{H}_{\mathrm{MS}} \quad-\mathrm{H}_{\mathrm{BG}}-\sum_{\text {Kcorr }}$

where $L$ is the median Path loss in $d B, L_{S L}$ is the free space loss in $d B, X_{M U}$ is median attenuation in $d B, H_{M S}$ is mobile station antenna height gain factor, $H_{B G}$ is base station antenna height gain factor and $K_{\text {corr }}$ is the correction factor gain (such as type of environment, water surfaces, isolated obstacle etc.).

\subsection{Multipath Fading and Interference}

In any wireless communication channel the signal travels from transmitter to receiver over multiple paths which causes fluctuations in phase, angle of arrival and amplitude of the received signal, thus gives rise to multipath fading. In order to mitigate the effects of fading in the wireless channel, a model is required to predict the effects accurately.

\section{Simulation Environment}

In the present work, the simulation of OFDM system is performed for different wavelet families such as Haar, Biorthogonal, Daubechies and Reverse-Biorthogonal for the joint effect of path loss, multipath fading and noisy environment of the wireless channel in mobile WiMAX system. The simulation parameters for different wavelet families of DWT for the proposed design are presented in Table 1 . The proposed system is simulated in MATLAB for 16-QAM modulation scheme with $3 / 4$ rate convolutions encoding using different Path loss models such as Hata Model and Okumura Model. The proposed system was modeled for mobile WiMAX system and performance is evaluated in terms of BER for different order of wavelet families in comparison with the FFT based OFDM system. The parameters considered to predict path loss of WiMAX signal are presented in Table 2.

Table1. Simulation Parameters

\begin{tabular}{|c|c|}
\hline Parameters & Value \\
\hline Modulation Scheme & 16- QAM $3 / 4$ \\
\hline \multirow[t]{4}{*}{ DWT Families } & 1) Daubechies : db1, db3, db5, db8 \\
\hline & 2) Biorthogonal $:$ bior2.6, bior 3.5, bior5.5, bior6.8 \\
\hline & $\begin{array}{l}\text { 3) Reverse -Biorthogonal : rbio2.4, rbio 3.3, rbio 5.5, } \\
\text { rbio } 6.8\end{array}$ \\
\hline & 4) Haar \\
\hline Path loss Model & $\begin{array}{ll}\text { 1) } & \text { Hata model } \\
\text { 2) } & \text { Okumura Model }\end{array}$ \\
\hline Channel model & Rayleigh fading +AWGN \\
\hline No. of Symbols & $50-100$ \\
\hline
\end{tabular}


Table 2. Mobile WiMAX System Parameters

\begin{tabular}{|c|c|}
\hline Parameters & Value \\
\hline Frequency band & $2.3 \mathrm{GHz}$ \\
\hline $\begin{array}{c}\text { Distance between transmitter and } \\
\text { receiver antenna height }\end{array}$ & $1-10 \mathrm{Km}$ \\
\hline Transmitter Antenna Height & $150 \mathrm{~m}$ \\
\hline Receiver Mobile Terminal Height & $5 \mathrm{~m}$ \\
\hline Environment & Suburban \\
\hline
\end{tabular}

\section{Simulation Results and Discussion}

The performance of DWT based OFDM system for different orders within the same wavelet family for $16-\mathrm{QAM} 3 / 4$ system considering path loss model with fading channel conditions is measured in BER curves. A comparative performance analysis of the results obtained from different wavelet families has also been carried out.

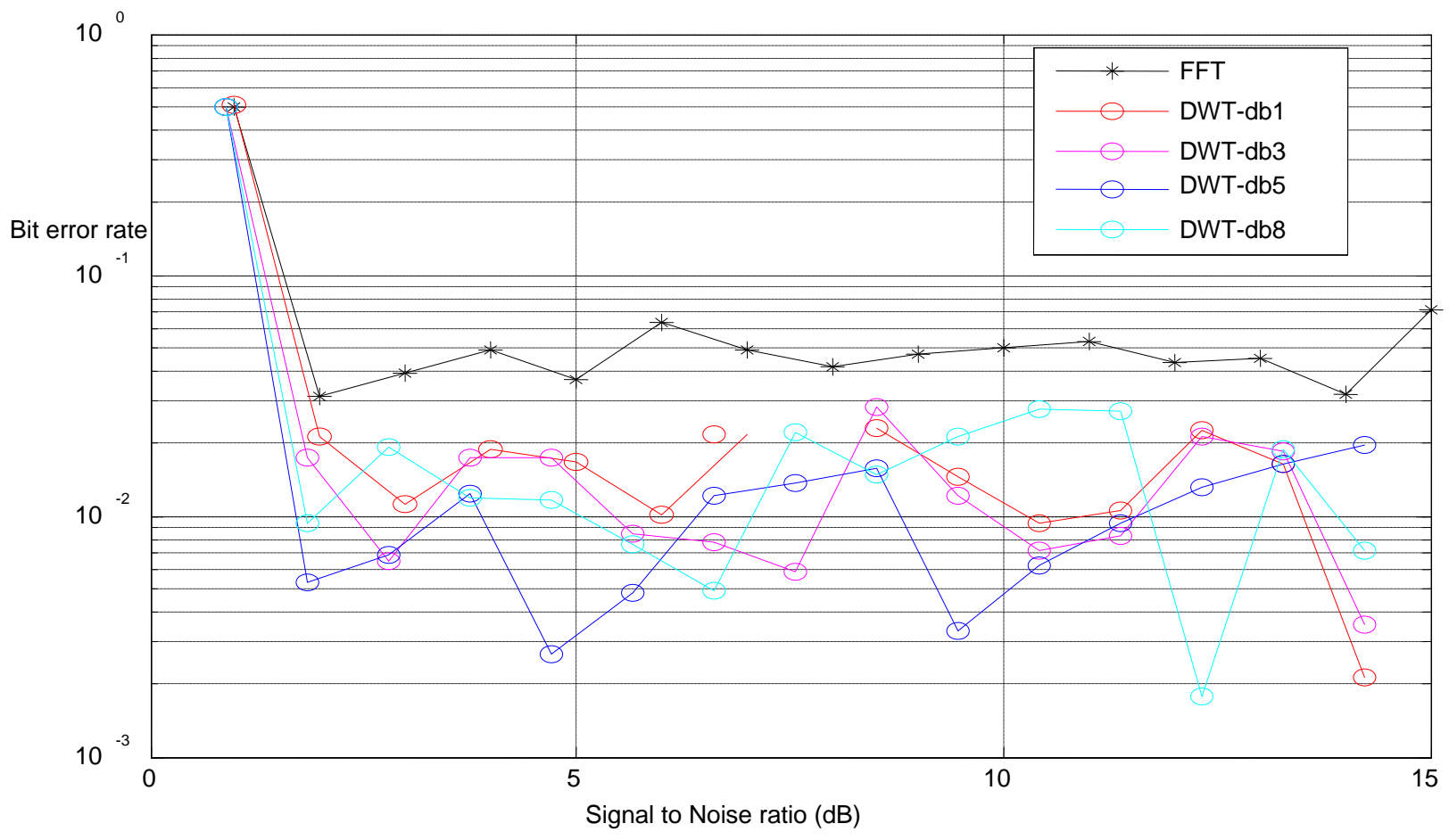

Figure 3(a): Performance of DWT-based OFDM System for Different Orders of Daubechies wavelet Family using Hata Model 


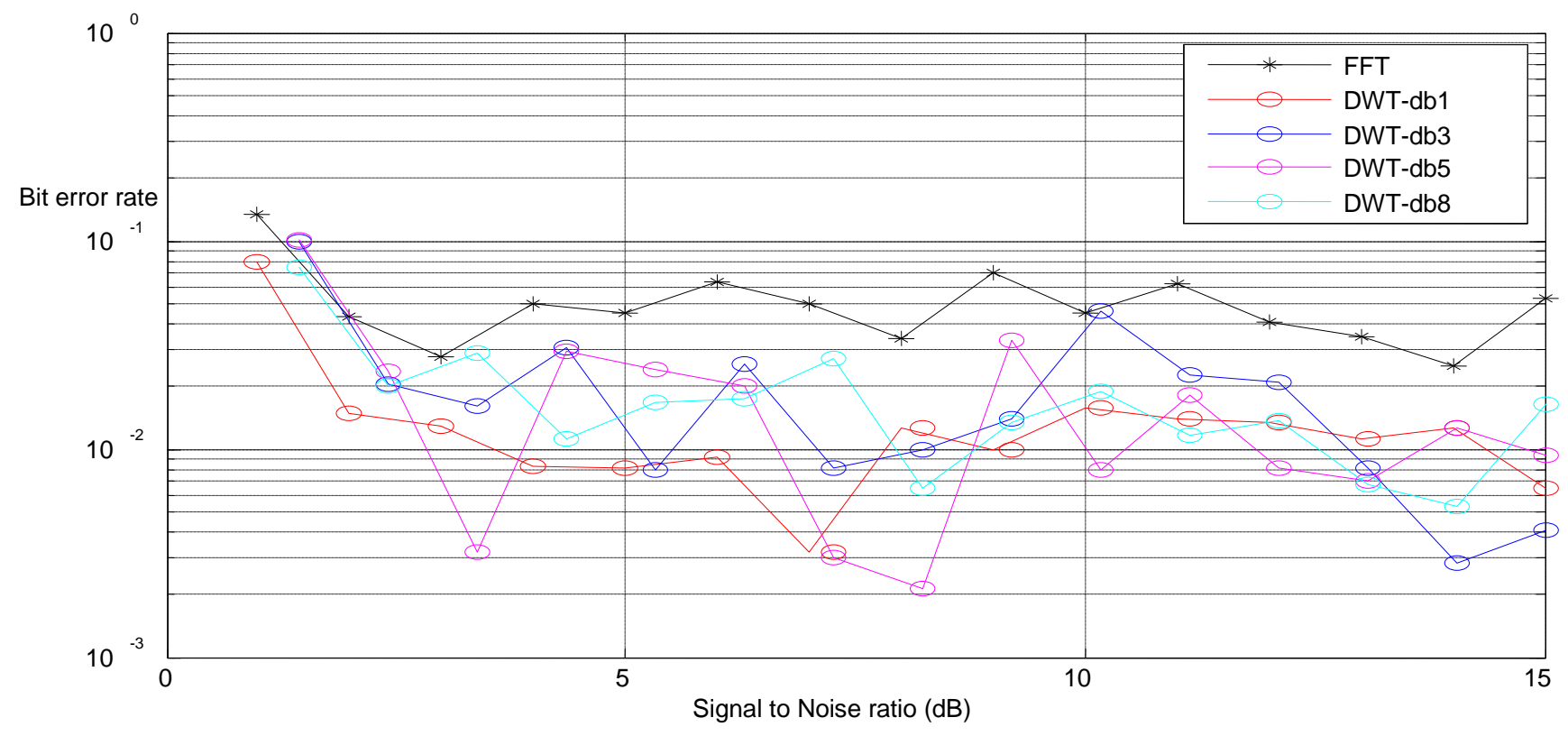

Figure 3(b): Performance of DWT-based OFDM System for Different Orders of Daubechies Wavelet Family using Okumara Model

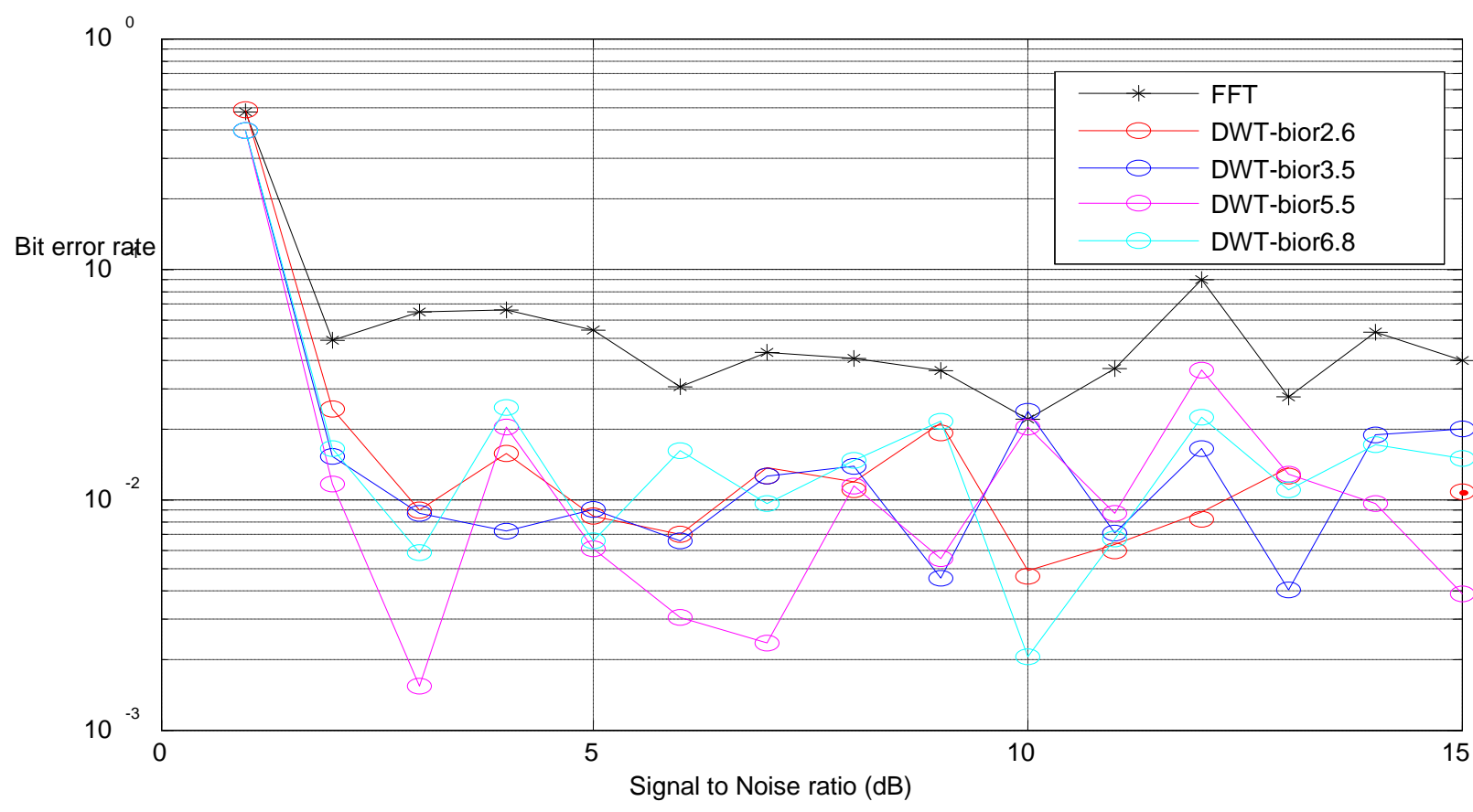

Figure 4(a): Performance of DWT-based OFDM System for Different Orders of Biorthogonal Wavelet Family using Hata Model 


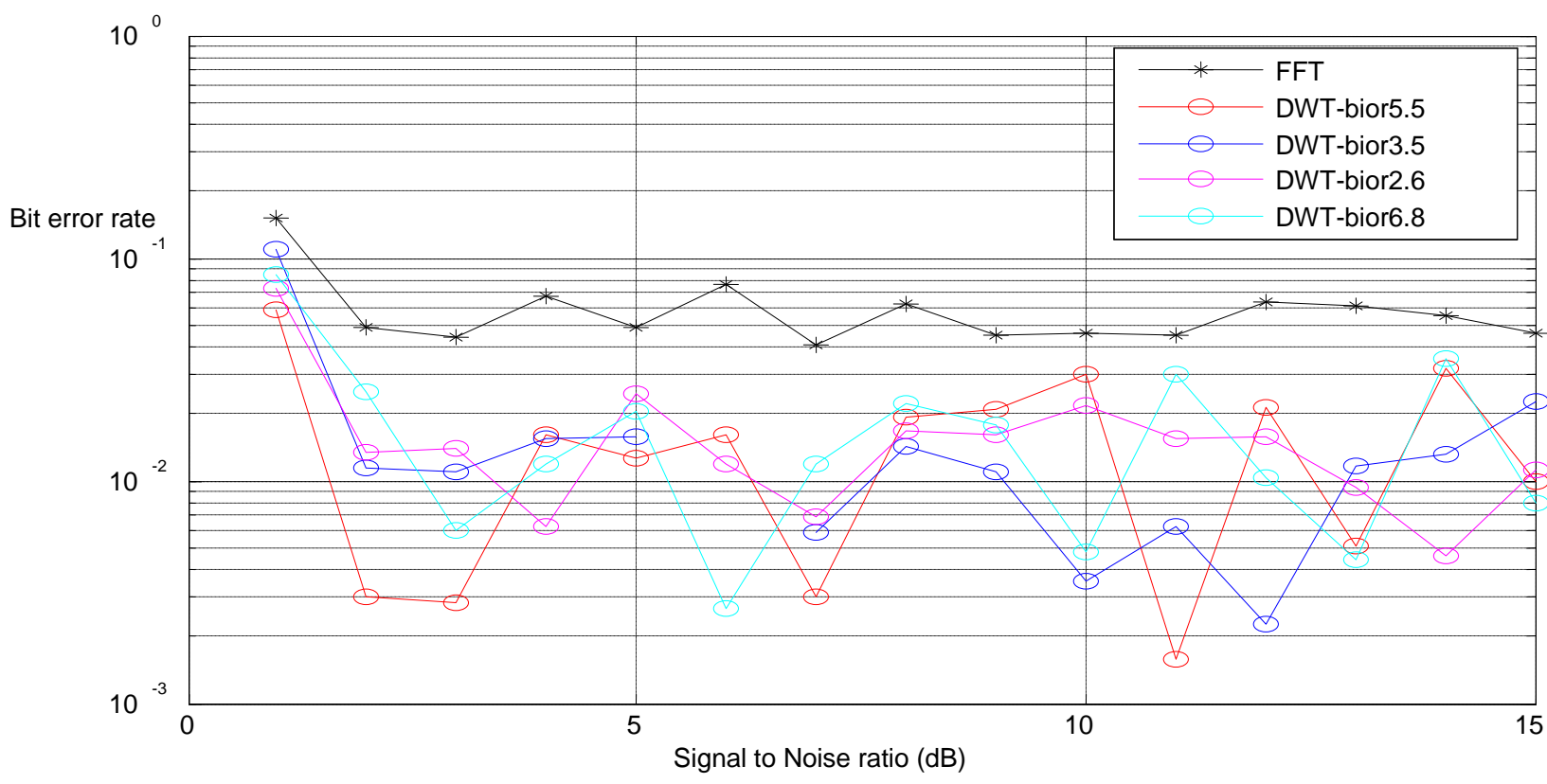

Figure 4(b): Performance of DWT-based OFDM System for Different Orders of Biorthogonal Wavelet Family using Okumara Model

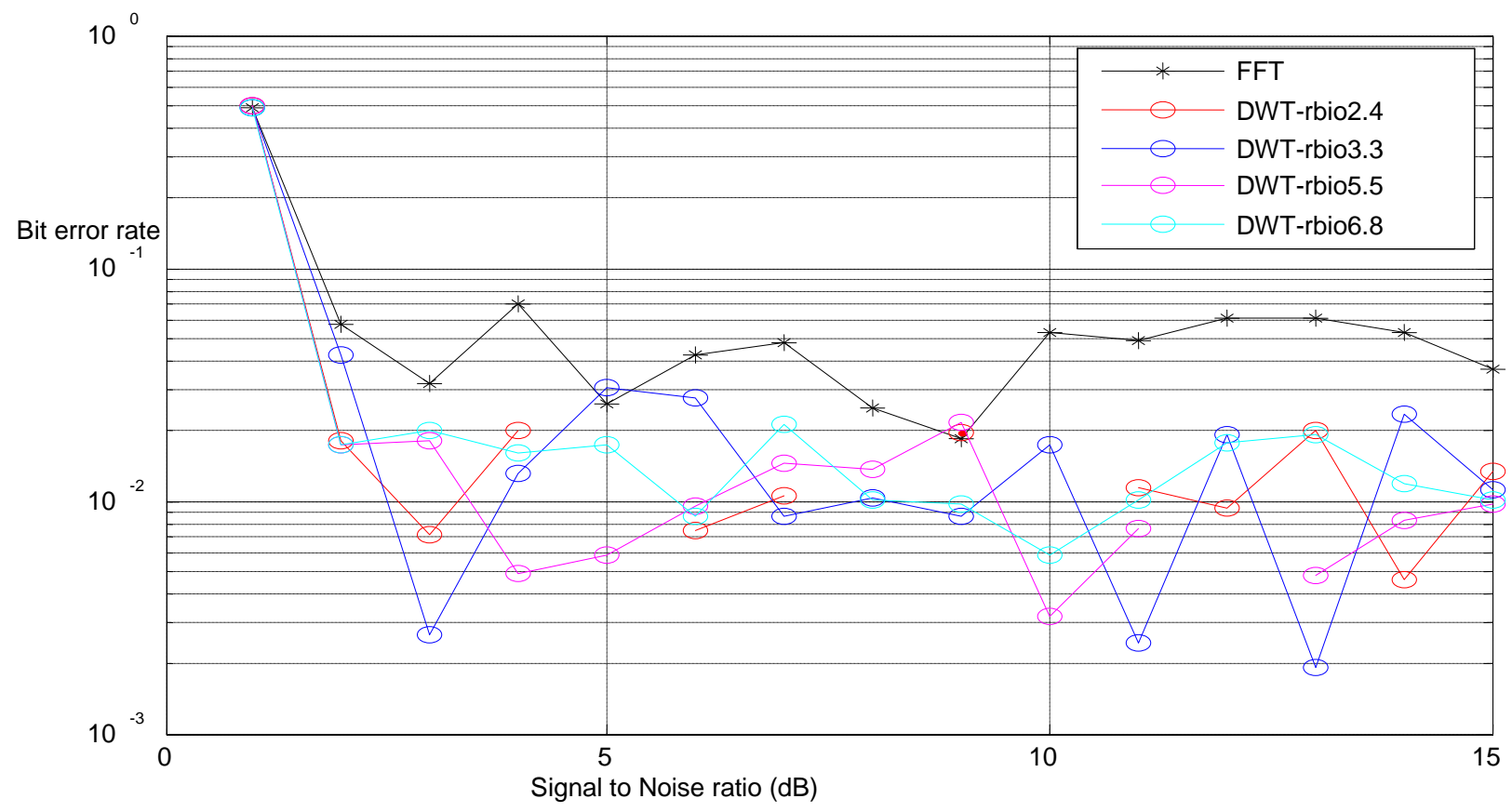

Figure 5(a): Performance of DWT-based OFDM System for Different Orders of Reverse-Biorthogonal Wavelet Family using Hata Model 


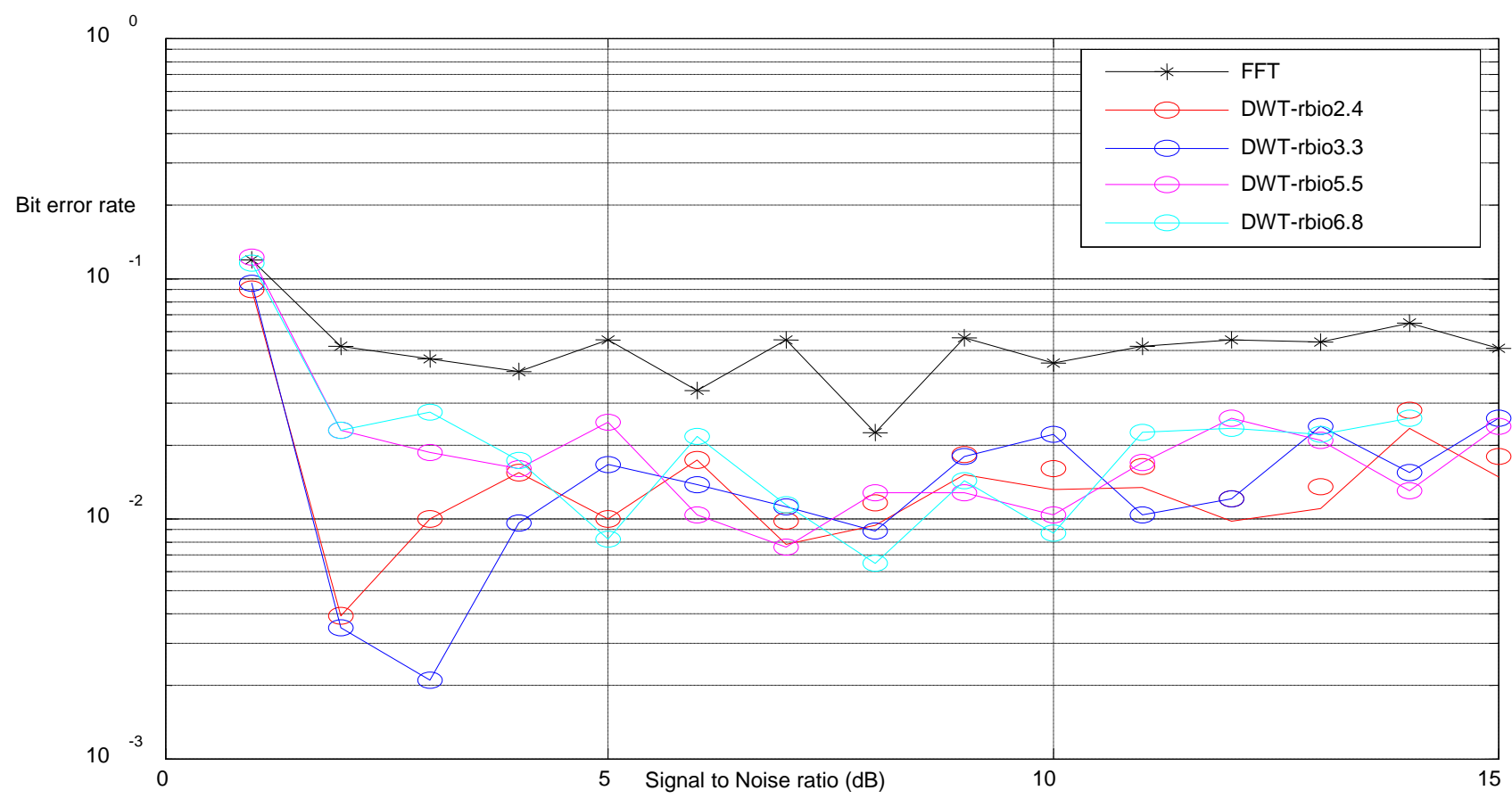

Figure 5(b): Performance of DWT-based OFDM System for Different Orders of Reverse-Biorthogonal Family using Okumara Model

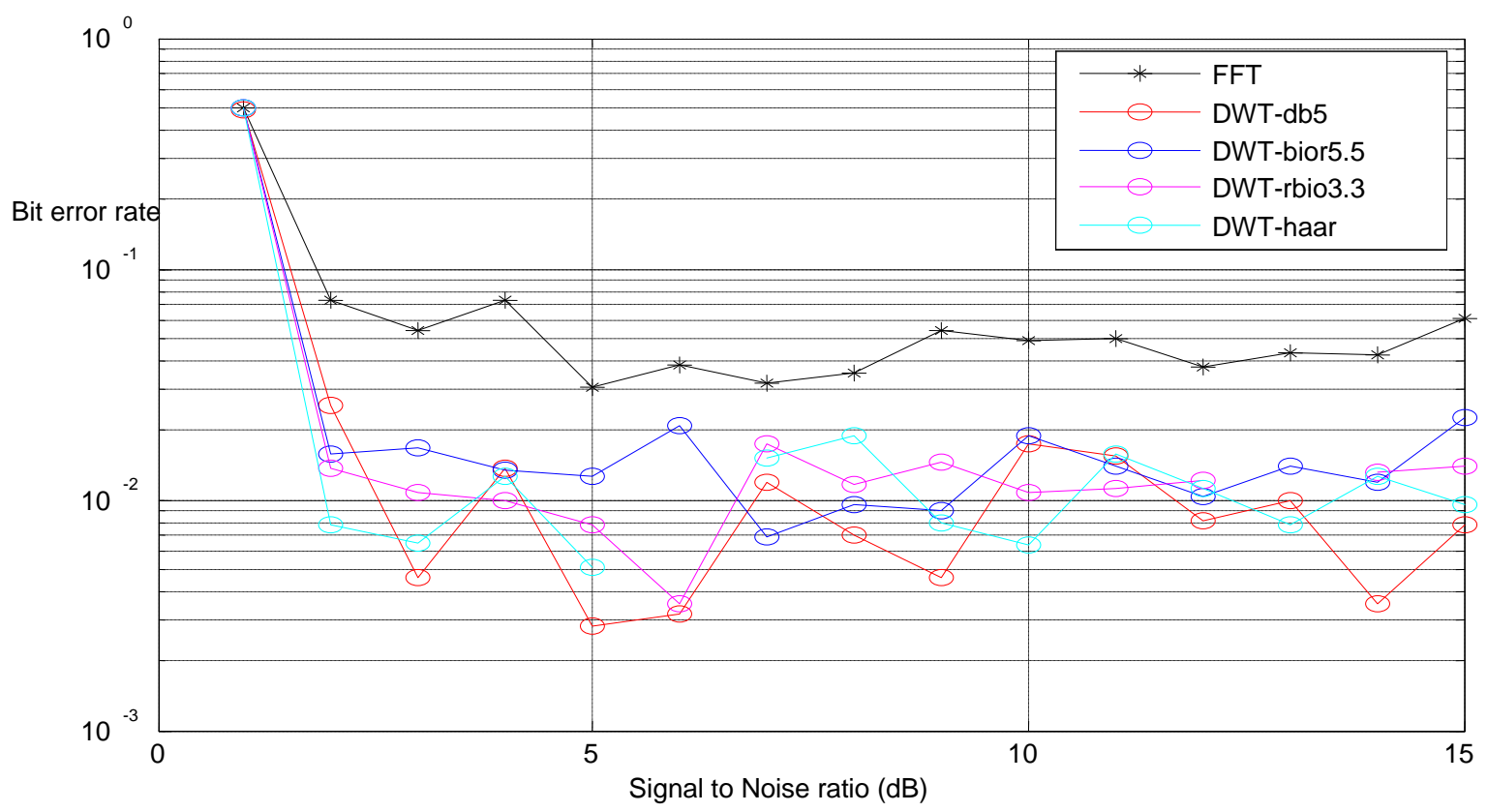

Figure 6(a): Performance of DWT-based OFDM System for Comparison of Haar, db5, rbio3.3 and bior5.5 Wavelets using Hata Model 


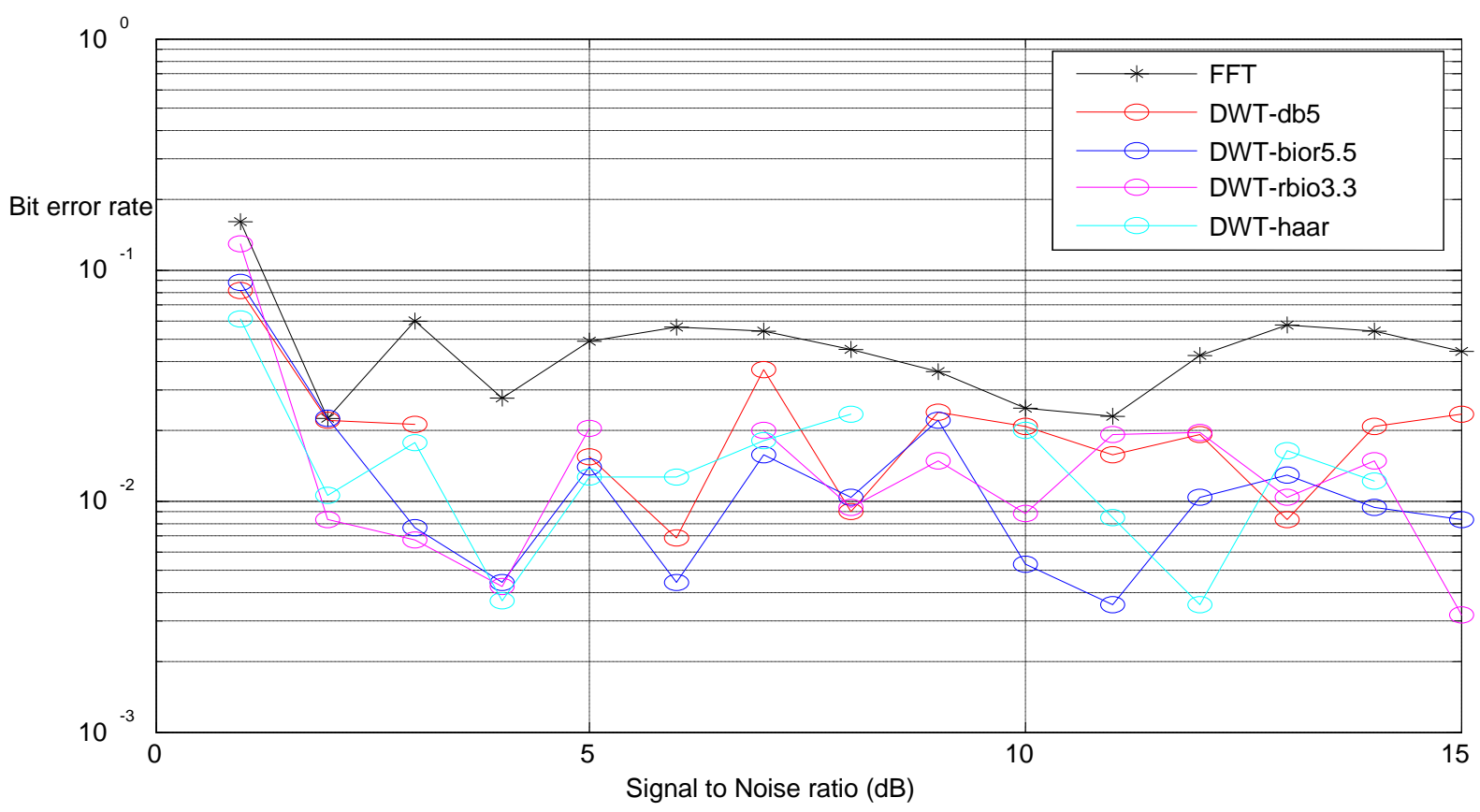

\section{Figure 6(b): Performance of DWT-based OFDM System for Comparison of Haar, db5, rbio3.3 and bior5.5 Wavelets using Okumara Model}

The performance of different orders of Daubechies wavelet family such as db1, db3, $\mathrm{db} 5$ and $\mathrm{db} 8$ is presented in Figure 3(a-b) for Hata and Okumara Path loss model respectively. In both these cases best results are found for $\mathrm{db} 5$ in the Daubechies wavelet family. Figure 4(a-b) compares the performance of different orders of Biorthogonal wavelet family such as bior2.6, bior 3.5, bior5.5 and bior6.8 obtained for Hata and Okumara Path loss model respectively and it is observed that bior5.5 has lower BER in Biorthogonal wavelet family. Figure 5(a-b) shows the performance of different orders of Reverse-Biorthogonal wavelet family such as rbio2.4, rbio 3.3, rbio 5.5 and rbio 6.8. The results obtained depicts that rbio3.3 has lower BER for mostly tested SNR in Reverse - Biorthogonal wavelet family. Further comparison of wavelet families such as Haar, db5, rbio3.3 and bior5.5 is carried for as shown in Figure 6(a-b) for Hata and Okumara Path loss model respectively. The results shows that Biorthogonal wavelet bior5.5 gives better performance for Okumara model and Daubechies wavelet db5 works well for Hata model as compared to other wavelets

\section{Conclusion}

In this paper, simulation is carried for different widely used wavelets namely Haar, Daubechies, Biorthogonal and Reverse-Biorthogonal based OFDM systems and compared their performance with conventional OFDM system analyzing the joint impact of path loss, multipath fading and noise on mobile WiMAX. Comparison and analysis of BER has been done for 16-QAM 3/4 system using both Hata and Okumara path loss models. Wavelet based OFDM system is a very flexible system which is also simple, and has a low complexity as only low order filters are needed instead of complex FFT processors. To simulate the influence of multipath fading, and interference noise on this network, appropriate channel model is considered. And it is inferred that DWT-OFDM is better as compared to FFT-OFDM for all wavelets with regards to the BER performance but Biorthogonal wavelet performance is superior with Okumara model and with Hata model, Daubechies wavelet outperforms other wavelets. 


\section{References}

[1] Y. Li and G.L.Stuber, Editors, "Orthogonal Frequency Division Multiplexing for wireless Communication", Springer, (2006).

[2] S. Khalid and S. I Shah. Editors, "PAPR Reduction by using discrete wavelet transform", Proceeding of IEEE $-2^{\text {nd }}$ International Conference on Emerging Technologies, (2006); Peshawar.

[3] W. Saad, N. El-Fishawy, S.EL-Rabaie, and M. Shokair, "An Efficient Technique for OFDM system using Discrete Wavelet Transform", Springer-Verlag Berlin Heidelberg, (2010), pp. 533-541.

[4] K.Abdullah and Z. M .Hussain, Editors, "Performance of Fourier-Based and Wavelet-Based OFDM for DVB-T Systems", Proceedings of Australasian Telecommunication Networks and Applications Conference, (2007); Christchurch, New Zealand, pp. 1-5.

[5] K. Abdullah and Z. M Hussain, Editors, "Studies on DWT-OFDM and FFT-OFDM Systems", Proceeding of IEEE International Conference on Communication, Computer and Power, (2009).

[6] D. Gupta, V. Vats and K. K., Garg, Editors, "Performance Analysis of DFT-OFDM, DCT-OFDM, and DWT-OFDM Systems in AWGN Channel", Proceedings of International Conference on Wireless and Mobile Communications, (2008); Washington, USA.

[7] U.Khan, S.Baig, and M. J.Mughal, Editors, Performance comparison of wavelet packet modulation and OFDM for Multipath wireless channel, Proceedings of IEEE $2^{\text {nd }}$ International Conference on Computer, Control and Communication, (2009); Karachi,

[8] M. Oltean and M. Nafornita, Editors, "Wavelet OFDM performance in frequency selective fading channels", Proceedings of IEEE $8^{\text {th }}$ International Conference on Communications, (2010); Bucharest, Romania.

[9] H. J. Taha.and M. F. M Salleh, "Performance comparison of wavelet packet transform and FFT-OFDM system based on QAM modulation parameters in fading channels", Wseas Transactions on Communications, vol. 9, no.8, (2010), pp 453-462.

[10] T. Helaly, R. Dansereau and M. El-Tanany, "BER Performance of OFDM Signals in Presence of Nonlinear Distortion due to SSPA", Wireless Personal Communications, vol. 64, no.4, (2012), pp 749-760.

[11] S.A. Broughton and K. Bryan, Editors, "Discrete Fourier analysis and wavelets", John Wiley Publishers, (2009).

[12] O. Anoh , R. A. Abd-Alhameed, S. M. Jones , Y. A. S Dama and . M. S. Binmelha, "The Wavelet Families for OFDM System - Comparisons over AWGN and Rayleigh Channels, Personal Satellite Services", Lecture notes of the Institute for Computer Sciences, Social Informatics and Telecommunication Engineering, vol. 52, (2013), pp 61- 68.

[13] M.K. Gupta and S.Tiwari, "Performance evaluation of conventional and wavelet based OFDM System", International Journal on Electronics and Communication, vol. 67, no.4, (2013), pp. 348-354.

[14] V. Kumbasar and O.Kucur, "Performance comparison of wavelet based and conventional OFDM systems in multipath Rayleigh fading channels”, Digital Signal Processing, vol. 22, (2012), pp 841-846. 
International Journal of Future Generation Communication and Networking Vol. 8, No. 1 (2015) 